Research Note:

\title{
Abundance and prey spectrum of web spiders in rice agroecosystems of Pangasugan, Leyte, Philippines
}

\author{
Sarwshri Gangurde', Konrad Martin' and Maria Juliet C.Ceniza ${ }^{2}$ \\ 'Institute of Plant Production and Agroecology in the Tropics and Subtropics \\ (380), University of Hohenheim. Stuttgart, Germany: 'Institute of Tropical Ecology, \\ Visayas State University: Baybay (ity: Leyte. Philippines
}

\section{ABSTRACT}

The cultivation of tropical Asian rice. which may have originated 9,000 years ago, created an agricultural ecosystem of unrivalled ecological complexity. A complex arthropod communitiy is inhabiting in the rice ecosystem, including pest and beneficial species. Concerning beneficials, the spiders are among the very commonly encountered species. A study was conducted in the irrigated tropical rice fields of Leyte, Philippines on the abundance and their potential for natural biological control. The objective of this study was to record, identify and count individuals of selected web building spider species and evaluate the prey spectrum at different stages of rice growth. It was observed that abundance of spiders in the rice ecosystems occurred only starting at the tillering stage when the preferred host plant stage for the prey species was reached. The most dominant species of spiders encountered were Tetragnatha species. However, in the latest stage of rice development, Argiope species were the most dominant spiders. Prey species included mainly the pest species of the rice plants, such as the hoppers, rice bugs and other smaller insects and in addition the other predatory species such as the coccinellid beetles, dragonflies and parasitic hymenopterans were also observed. The web building spiders showed more activity in the late afternoon than in early morning.

Keywords: Tetragnatha, Argiope, prey spectrum, ricefields, spider fauna

Correspondence: S. Gangurde Address: Institute (380). University of Hohenheim, Garbenstrasse 13, D-70599, Stuttgart, Germany.E-mail:svgang@uni-hohenheim.de

DOI: $10.32945 /$ atr29210.2007 


\section{INTRODUCTION}

Spiders are a highly species rich group of invertebrates that exploit a wide variety of niches in virtually all the earth's biomes. Some species of spiders build elaborate webs that passively trap their prey. Given spiders taxonomic diversity as well as the variety of ecological niches breadth along with the ease of catching them, spiders can represent useful, fairly easily measured indicators of environmental change and community level diversity (Coddington and Levi, 1991). This paper focuses on analyzing web building spider communities with a main objective of analyzing the potential of these natural enemies for the control of rice pests and its application in decision making for biological control.

\section{MATERIALS AND METHODS}

This study was conducted in Baybay City in the western part of Leyte, Philippines. Leyte island is one of the Visayas island group located approximately between $124^{\circ} 17^{\prime}$ east longitude and between $9^{\circ} 55^{\prime}$ and $11^{\circ} 48^{\prime}$ north latitude. Two sampling sites were established. One area was located in the vicinity of the Visayas State University (VSU) campus at the ricefields adjacent to theAgroforestry Demo Farm and the second area was located in Barangay Pangasugan about $2.3 \mathrm{kms}$. north from the VSU administrative headquarters which is also an LSU's experimental plot. The first site was near an upland contour demo farming system planted to leguminous hedgerows and the alleys were planted with annual crops. Stands of old native trees also existed in the area. The ricefield sampling areas lay adjacent to the demo farm at the lower slope at an elevation of around 10-15 meters above sea level. The second site was located in a communal farmers rice fields in the neighboring barangay which is an experimental plot of VSU. The surrounding areas are all ricefields.

For the observation of the spider activity, 3 plots measuring $100 \mathrm{~m}^{2}$ were established on each sampling site. On each of the plots, two subplots measuring $1 \mathrm{x} 1 \mathrm{~m}$ were also established. Bamboo stakes were placed on the four corners of the subplots as permanent markers. Observations of the prey spectrum of the web spiders was done by recording the number of preys caught in each web. The preys were collected and identified in the laboratory. The pattern of 
web huilding as well as the mode of attack of the spiders on its prey were also noted. Observations were made for two day's a week every Wednesday and Saturday in the morning at 6.30 am and 8.30 am and in the afternoon at 4.30 $\mathrm{pm}$ and $6.00 \mathrm{pm}$. Data gathering and observations were made throughout the different stages of rice growth.

\section{RESULTS AND DISCUSSION}

\section{Abundance and prey spectrum of observed spider fauna}

Figures 1 and 2 show the abundance of spider fauna recorded in the sampling sites. The data showed that only three species of web building spiders were observed in the sampling sites, namely: Argiope sp, Tetragnatha sp. and Araneus sp. During the early growth (seeding) stage, no web-building spiders were observed in both sites, however during the tillering and milking stages Tetragnatha spiders were found to be dominant in the two sites observed and even up to maturity at site 2 . Other species observed occurred in relatively few numbers only, although at rice maturity Argiope spiders were most common, particularly in site 1 .

Baldissera et al. (2004) mentioned that web spider assemblages are influenced by an edge gradient, and is strongly related to vegetation features. At tillering and milking stage, a number of prey species individuals is high because of the onset of the vegetative and reproductive stage of the rice plants, respectively. Luscious vegetative growth of rice attracts a diverse population of pest species. Field observations showed that most of the prey species found trapped in the spider webs of Tetragnatha mainly included leafhoppers (Nephotettix spp.), leaf bugs (Eysarcoris), other cicadellids and planthopper species, some species of Diptera and larvae of Lepidoptera. Furthermore, it was also observed that predatory and parasitic species of insects add to the prey spectrum of the spider fauna in the rice ecosystems. These were the predator species such as carabid beetles, ladybird beetles (Micraspis crocea), dragonflies (Agriocnemis spp), rice bugs (Leptocorisa sp.), and parasitic Hymenoptera. This is probably the reason why Tetragnatha were mostly abundant during these stages of rice growth. 
Argiope species, on the other hand were found to prey also on hoppers and cicadellid species in addition to lady bird beetles which can enter the lower canopy of the plants. However, for the Araneus spp., it was observed in minor occurrence probably because these species used to build their webs at the most lower canopy of the plant due to the less abundance and emergence of detrital arthropods (Miyashita et al., 2003).

At maturity when the rice ripens, some of the prey species migrate to other alternate food sources, probably in the vicinity of the rice fields where weeds are present. However, for site 2, the continued abundance of Tetragnatha can be accounted to the continuous cropping practices of rice in the site. The area has an assynchronous planting system so that all stages of the rice plant can be found in the site. Spider species abound for they find it easier to catch prey in the vicinity.

In the field, Tetragnatha spp. was especially found to be very effective on feeding once the prey is caught (Figure 1). A number of preys caught in its web varies from one to many individuals. This may be due to the web decoration by Tetragnatha spp. Bruce et al. (2004) observed that under certain conditions decorated webs capture more prey per web area than undecorated webs. It was observed that Tetragnatha spp. used to build their webs in the middle canopy of the plant as compared to other observed species. But because of the heavy rains that occured before observations were taken at site lduring maturity stage, Tetragnatha spp. failed to survive in a temporary floody conditions and was not recovered during the observation period at site 1 . This might be the reason that Tetragnatha spp. population dropped and so were the webs. As Tetragnatha spp. was found building webs in the lower canopy of the plants, and most of the insect pests were usually trapped in the upper canopy, Tetragnatha spp. webs found in the middle canopy were not be able to trap enough prey for their survival. This might also be the reason that Tetragnatha spp. abundance dropped during maturity stage in site 1 as compared to site 2 . During the 10 th week of growth, when the crop reached maturity stage, site 1 was treated with insecticide causing the Tetragnatha spp. population to drop as compared to the other species which were found to stay in the middle canopy of the plant. Insecticide spraying caused unavailability of food to the entire web building spider population, hence the drop in Tetragnatha spp. population. 

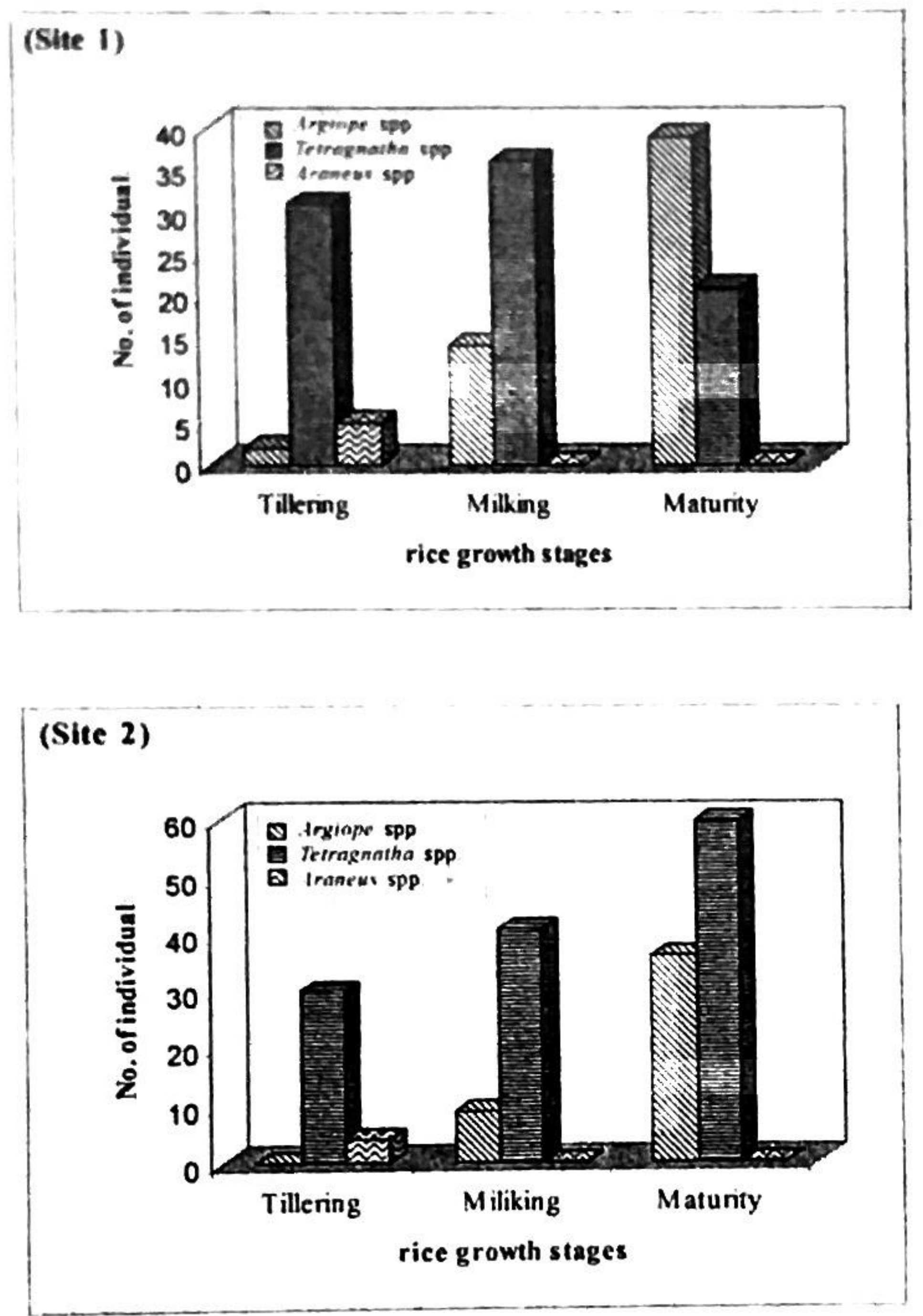

Figure 1. Abundance of web building spiders at different stages of plant growth in Sites land 2 
Ficld observations also showed that it was hard to identify the pest species of rice and beneficial ones, as most of the time the prey was covered with the white silky and sticky substance produced by the spiders. According to Nakata and ( shimaru (2004), it is al so hard to estimate the approximate prey spectrum of the web spiders as spiders sometimes relocate their webs and relocation rate differs among species.

It was also observed that during the rainy days spiders used to remain inactive, no webs building took place especially after the heavy rains. This is supported by the statement by You (1997) that total species in the community varied with each field type because of the influence of the environmental variables and fluctuated with the various growth stages of rice. Spiders used to remain active especially from 6:00 until 10:00 in the morning. As the area gets warmer due to the heat of the sun, the spiders used to hide under the shade for the whole afternoon to protect themselves from severe sunlight and became active again in the late afternoon after $4: 30$ or 5:00 pm in afternoon. Generally all species of the web building spiders have same behaviorial pattern on web building and mostly they are active in building the webs during late afternoon.

Spiders have been known to eat their own offspring's (Vreden \& Ahmadzabidi, 1986), however, this was not observed in this study probably due to the sufficient availability of food during the day time. The unavailability of food during night time might enhance the feeding of their offsprings. Normally the observation concluded that most of the web spiders used to attack the prey and feed on it at the same time. It is concluded that seldom prey was left hanging on the web. Shepard et al. (1987) reported that orb spiders make webs and collect whatever entered the web throughout the day and night.

Observations showed that there is a range of 1 to 4 spiders webs observed in the observation plots in the two sites, with least number recorded during the maturity stage rice. This coincides with the previous discussion on the number of individual spiders recorded for the two sites at various stages of rice growth (Table 1). 
Table 1 . Average number of spider webs for $|x|$ sq.m observation subplots in the two sites and standard deviation (S.D) and coefficient of variation (CV)

\begin{tabular}{|c|c|c|c|c|c|c|c|}
\hline Site 1 & Plot 1 & Plot 2 & Plot 3 & Total & Mean & S.D & $\mathrm{CV}$ \\
\hline Tillering & 2 & 3 & 5 & 10 & 3.33 & 1.52 & 45.64 \\
\hline Milking & 1 & 3 & 3 & 7 & 2.33 & 1.32 & 56.65 \\
\hline Maturity & 0 & 1 & 2 & 3 & 1 & 0 & 0 \\
\hline Sitc 2 & Plot 1 & Plot 2 & Plot 3 & Total & Mean & S.D & $\mathrm{CV}$ \\
\hline Tillering & 2 & 7 & 4 & 13 & 4.33 & 6.32 & 145.95 \\
\hline Milking & 2 & 4 & 3 & 9 & 3 & 0 & 0 \\
\hline Maturity & 2 & 3 & 2 & 7 & 2.33 & 0.33 & 14.16 \\
\hline
\end{tabular}

\section{CONCLUSION}

In rice agroecosystems, where there is favorable and abundant availability of prey species at almost all stages of rice growth, web building spiders also occurred in fair abundance. From the results of the study, spiders do have a wide spectrum of prey species, being generalist predators. The main prey species present in the ricefields included most of the plant and leafhoppers, flies, Lepidoptera larvae, parasitic hymenopterans, coccinellid and other species of beetles.

The structure and location of the webs of the spiders influenced the activity and the type of prey trapped. Tetragnatha spp. showed fast activity in building decorated webs and showed aggressiveness in attacking the prey quickly at any corner of the web as soon as it gets trapped into the web. Almost all recorded spider species (Tetragnatha, Argiope and Araneus) were found active in the late afternoon which concludes that there was enough availability of the prey species in the afternoons than in the morning. This study demonstrated that under that natural biological control, it is hard to use spiders singly as a means of pest control as it can trap pest as well as predators in their webs. The efficiency of controlling the pests is too low,however, using particular predators feeding on the particular pest species in the rice agroecosystem is considered to be satisfactory. 


\section{ACKNOWLEDGMENT}

The Eiselen Masters Research Grant from the Eiselen Foundation, Ulm, Germany funded this work and the facilities provided by the Visayas State University, Philippines for conducting this study are greatly acknowledged.

\section{REFERENCES}

BALDISSERA R., G. GANADE and S.B. FONTOURA. 2004. Web spider community response along an edge between pasture and Araucaria forest. Biological Conservation 118 (3): 403-409.

BRUCE M.J., A.M. HEILING and M.E. HERBERSTEIN. 2004. Web decorations and foraging success in 'Araneus' eburnus (Araneae : Araneidae). Annales Zoologici Fennici 41 (4): 563-575.

CODDINGTON J.A. and H.W. LEVI. 1991. Systematics and evolution of spiders (Araneae). Annual Review of Ecology and Systematics 22: 565-592.

DIDONET J., A. P. DIDONET, E. L. ERASMO and G.R. SANTOS. 2001. Incidence and population dynamics of pests and their natural enemies in upland rice in Gurupi, Tocantins. - Bioscience Journal. 17(1): 67-76.

MAYASHITA T., M. TAKADA and A. SHIMAZAKE. 2003. Experimental evidence that aboveground predators are sustained by underground detritivores. Oikos 103 (1):31-36.

NAKATA K. and A. USHIMARU. 2004. Difference in web construction behavior at newly occupied web sites between two Cyclosa species. Ethology 110 (5): 397 411.

SHEPARD B.M., A.T. BARRION and J.A. LITSINGER. 1987a. Helpful insects, Spiders and Pathogens. - International Rice Research Institute (IRRI), Los Banos. pp 145.

VREDEN G. and A. L. AHMADZABIDI. 1986. Pests of rice and their natural enemies in Peninsular Malaysia. Pudoc Publishers. pp 15-19.

YOU M.S. 1997. The species richness and diversity of the arthropod communities in rice fields. Entomologia-Sinica. 4(3): 238-248. 